\title{
Relationship of High Work Engagement among Staff Midwives with Their Immediate Superiors' Burnout on Maternity and Labor Wards in Japan
}

\author{
Emiko Kawauchi' ${ }^{1}$, Reiko Inoue ${ }^{2}$, Kazutomo Ohashi ${ }^{1}$ \\ ${ }^{1}$ Department of Children and Women's Health, Division of Health Sciences, Osaka University Graduate School of Medicine, Suita, \\ Japan \\ ${ }^{2}$ Former Local Incorporated Administrative Agency, Kobe City Hospital Organization, Kobe, Japan \\ Email: ohashi@sahs.med.osaka-u.ac.jp
}

How to cite this paper: Kawauchi, E., Inoue, R. and Ohashi, K. (2017) Relationship of High Work Engagement among Staff Midwives with Their Immediate Superiors' Burnout on Maternity and Labor Wards in Japan. Open Journal of Nursing, 7, 39-49.

http://dx.doi.org/10.4236/ojn.2017.71004

Received: December 6, 2016

Accepted: January 15, 2017

Published: January 18, 2017

Copyright () 2017 by authors and Scientific Research Publishing Inc. This work is licensed under the Creative Commons Attribution International License (CC BY 4.0).

http://creativecommons.org/licenses/by/4.0/ (c) (i) Open Access

\begin{abstract}
Introduction: Mental conditions for work among workers are related to clinical performance and influenced by colleagues within the same workplace. The aim of study was to examine the work engagement and burnout of staff midwives working on maternity and labor wards and to determine the factors related to high work engagement of staff midwives, including their immediate superiors' work engagement and burnout. Methods: A cross-sectional questionnaire survey was employed in Japan. Questionnaires were distributed to 452 midwives/nurses working on maternity and labor wards of 20 hospitals and responses from 96 staff midwives and 17 of their immediate superiors were analyzed. Work engagement and burnout (exhaustion, cynicism, and professional efficacy) were assessed by the Utrecht Work Engagement Scale and the Maslach Burnout Inventory-General Survey, respectively. To examine the association of work engagement among staff midwives with their ages, marital status and work engagement and burnout of their superiors, logistic regression analysis was conducted. Results: Immediate superiors showed significantly higher level of work engagement than staff midwives, while there was no difference in the burnout. High work engagement of staff midwives was significantly correlated with the professional efficacy (AOR 1.93, 95\% CI 1.12 - 3.33) and cynicism (AOR 2.01, 95\% CI, 1.04 - 3.90) of their immediate superiors. There was no correlation of work engagement between them. Conclusions: High work engagement of staff midwives was correlated to high professional efficacy and cynicism of their immediate superiors, suggesting that there might be crossover effects on mental conditions for work between staff midwives and their immediate superiors.
\end{abstract}




\section{Keywords}

Work Engagement, Burnout, Staff Midwives, Immediate Superiors

\section{Introduction}

Midwives working in maternity and labor wards have been shown to experience high levels of burnout and emotional stress [1] [2] [3] [4] [5]. Burnout from working has been used previously to assess workers' negative mental condition [6]. One of the most common scales for measuring burnout is the Maslach Burnout Inventory-General Survey (MBI-GS) in which burnout consists of exhaustion, cynicism, and professional efficacy [7].

In recent years, a positive mental condition for work has attracted attention, and Schaufeli developed the Utrecht Work Engagement Scale (UWES) which measures work engagement, that is, a positive psychological attitude to work [8]. He defined work engagement as a positive, fulfilling, work-related state of mind that is characterized by vigor, dedication and absorption. Schaufeli and Bakker [9] examined the conceptual framework of UWES with a job demands-resources model and the relationship between work engagement and burnout. The correlation between work engagement and burnout is mainly negative, but the authors did not refer to one underlying dimension. Professional efficacy as a subscale of burnout is also an element of work engagement, and work engagement and burnout do not negate each other but are independent [8] [9]. We thus need to examine the mental conditions for work among midwives working on the maternity and labor wards from both positive (work engagement) and negative (burnout) aspects.

Studies of work engagement for nurses are progressing and work engagement was reported to be related to employee performance and organizational management. In a review of work engagement among nurses, organizational factors versus individual contributors significantly impacted engagement at work [10]. Work engagement was also related to intention to remain among graduate nurses [11]. Additionally, in a meta-analysis for burnout, engagement, and safety at work [12], work engagement was positively related to safety climate for nurses [13]. From the viewpoint of patients, nurses' work engagement was significantly related to higher levels of patient satisfaction [14].

Work engagement and a professional nursing practice environment have a positive correlation [15], and it is necessary to analyze the correlation between them at a unit level [16] [17]. Within the same workplace, it has been noted that the burnout of staff and managers shows a crossover reaction [18], and teamlevel burnout and work engagement are related to individual team members' burnout and work engagement [19]. Supervisory relationships have the capacity to empower, inspire and motivate midwives [20], and a recent review in nursing concludes that supervisors' leadership and management influence work engagement of the staff [21]. However, it is unknown whether such a correlation exists 
for work engagement and burnout between staff midwives and their immediate superiors working on maternity and labor wards.

\section{Methods}

\subsection{The Aim}

We aimed to examine the work engagement and burnout of staff midwives working on maternity and labor wards and to determine the factors related to work engagement of staff midwives, including their immediate superiors' work engagement and burnout.

\subsection{Design and Setting of the Study}

This study was conducted as a cross-sectional questionnaire among midwives and nurses working on maternity and labor wards of hospitals in Hyogo prefecture, Japan. Hyogo Prefecture is located in western Japan. It has both urban and rural areas. In 2012, there were 46,436 live births, 22.7 midwives per $10^{5}$ population (25.0 in Japan) and 39.6 obstetricians per $10^{5}$ population (40.7 in Japan). Therefore, we selected this prefecture as being representative of the working environment of midwives, and implemented a complete survey. We listed all hospitals in Hyogo prefecture that deal with insurance under the Japan Obstetrics Compensation System for Cerebral Palsy, and requested participation in the study from the nursing directors of a total of 51 hospitals by mail. Twenty hospitals (39.2\%), including 7 maternal and child health $(\mathrm{MCH})$ centers and 13 general hospitals, agreed to participate in the study.

\subsection{Participants and Procedure}

Data were collected in September and November 2012. Questionnaires were distributed to 452 midwives/nurses who worked on maternity and labor wards. Scales of work engagement and burnout were also provided. Of the 452 midwives/nurses in 20 hospitals, 253 (56.0\%) including 170 staff midwives, 64 staff nurses and 19 head nurses/midwives returned responses by mail. The exclusion criteria of staff midwives were as follows: incomplete responses $(n=16)$, responses from part-timers $(n=13)$ and responses from midwives who did not work in maternity and labor wards $(n=5)$. To examine the correlation between staff midwives' work engagement and the mental condition of their superiors, we used responses from staff midwives whose superiors had also replied. Finally, we analyzed 96 staff midwives and 17 head nurses/midwives (immediate superiors) in 15 hospitals. There were two head nurses/midwives in the same wards of two hospitals, and their mean scores were used as a representative score of immediate superior in logistic regression analysis.

\subsection{Measurement}

The questionnaire consisted of demographic characteristics (age, years of experience, marriage, having a child, having an illness, working place, working hours, 
number of days off per month, and turnover intention) and the following two scales.

\section{Work engagement}

Work engagement was assessed using the short form of the Utrecht Work Engagement Scale (UWES) [22]. The UWES includes three subscales that reflect the underlying dimensions of engagement: vigor (3 items), dedication ( 3 items), and absorption (3 items). All items are scored on a seven-point Likert scale ranging from 0 ("never") to 6 ("always"). Shimazu et al. [23] developed the Japanese version and confirmed the internal consistency with 0.92 of Cronbach's alpha and the three-factor structure with 0.90 of GFI, 0.86 of AGFI, and 0.92 of CFI.

\section{Burnout}

Burnout was assessed using the Maslach Burnout Inventory-General Survey (MBI-GS) [7]. The MBI-GS includes three subscales: exhaustion (5 items), cynicism (5 items), and professional efficacy (6 items). All items are scored on a seven-point Likert scale ranging from 0 ("never") to 6 ("always"). High scores on exhaustion and cynicism and a low score on professional efficacy are indicative of burnout. The Japanese version was developed by Kitaoka et al. [24] and the Cronbach's alpha coefficient was 0.85 in exhaustion, 0.81 in cynicism, and 0.87 in professional efficacy. It preserved a three-factor structure similar to the original version $(\mathrm{GFI}=0.956, \mathrm{AGFI}=0.917$, $\mathrm{RMSEA}=0.086)$.

\subsection{Ethical Consideration}

The study was approved by the Ethical Committee of Health Sciences, Osaka University (No. 221). The anonymity of the participants was preserved.

\subsection{Data Analysis}

Characteristics of staff midwives and immediate superiors were compared. Age, years of experience, working hours, and number of days off per month were analyzed by $\mathrm{t}$-test. The proportion of marital status, parental status, workplace, and turnover intension were analyzed by chi-squared test.

The scores of UWES and MBI-GS were compared between staff midwives and immediate superiors using an unpaired t-test.

To examine the association of work engagement among staff midwives with their ages, marital status and work engagement and burnout of their superiors, logistic regression analysis was conducted using 96 staff midwives whose superiors returned complete questionnaires. UWES scores were divided into five categories: very high ( $\geq 5.51)$, high (4.67 - 5.50), average (2.89 - 4.66), low (1.78 $2.88)$, and very low $(\leq 1.77)[25]$. We then categorized very high and high as a high work engagement group (total score $\geq 4.67$ ) and the others as a low work engagement group (total score $\leq 4.66$ ). We used work engagement (low $=0$, high $=1$ ) as a dependent variable, and age, marital status (unmarried $=0$, married $=$ 1), superiors' total score of UWES, and each burnout score of exhaustion, cynicism, and professional efficacy as independent variables. Crude and adjusted odds 
ratios with $95 \%$ confidence intervals were calculated.

The data were analyzed using SPSS version 21 , and $\mathrm{p}<0.05$ was considered significant.

\section{Results}

The characteristics of participants are shown in Table 1. All participants were females. Immediate superiors were significantly older $(p<0.01)$ and more experienced $(p<0.01)$ than staff midwives. They had a child $(p=0.02)$ and an illness $(\mathrm{p}=0.01)$ more frequently. They worked longer hours $(\mathrm{p}<0.01)$ and took fewer days off ( $p<0.01)$ than staff midwives, but there was no difference in turnover intention between them $(\mathrm{p}=0.52)$.

Scores of work engagement and burnout were compared between staff midwives and immediate superiors (Table 2). In work engagement, immediate superiors showed significantly higher scores in total $(\mathrm{p}<0.01)$ and in all three subscales than the others $(\mathrm{p}=0.01$ in vigor, $\mathrm{p}=0.01$ in dedication, $\mathrm{p}<0.01$ in absorption). However, there was no difference in the three subscales of burnout.

The data of logistic regression analysis of high work engagement among staff midwives are shown in Table 3. The adjusted odds ratio (AOR) for the immediate superiors' cynicism was 2.01 (95\% CI, 1.04 - 3.90) and that for professional efficacy was 1.93 (95\% CI, 1.12 - 3.33). There was no correlation of work engagement between staff midwives and their immediate superiors

\section{Discussion}

This is the first report concerning work engagement assessed by the UWES and burnout by MBI-GS among Japanese staff midwives on maternity and labor

Table 1. Characteristics of staff midwives and immediate superiors (head midwives/ nurses) on maternity and labor wards.

\begin{tabular}{|c|c|c|c|c|}
\hline & Total & $\begin{array}{c}\text { Staff } \\
\text { midwives }\end{array}$ & $\begin{array}{l}\text { Immediate } \\
\text { superiors }\end{array}$ & p-value \\
\hline $\mathrm{N}$ & 113 & 96 & 17 & \\
\hline $\begin{array}{l}\text { Age (years) } \\
(\text { mean } \pm \mathrm{SD})\end{array}$ & $38.8 \pm 8.7$ & $37.4 \pm 8.4$ & $47.1 \pm 4.4$ & $<0.01$ \\
\hline $\begin{array}{l}\text { Experience (years) } \\
\quad(\text { mean } \pm S D)\end{array}$ & $14.1 \pm 8.3$ & $12.5 \pm 7.8$ & $23.0 \pm 4.7$ & $<0.01$ \\
\hline Married (n, \%) & $71(62.8)$ & $58(60.4)$ & $13(76.5)$ & 0.28 \\
\hline Having a child (n, \%) & $62(54.9)$ & $48(50.0)$ & $14(82.4)$ & 0.02 \\
\hline Having an illness $(\mathrm{n}, \%)$ & $23(20.4)$ & $15(15.6)$ & $8(47.1)$ & 0.01 \\
\hline \multicolumn{5}{|l|}{ Workplace (n, \%) } \\
\hline $\mathrm{MCH}$ center & $39(34.5)$ & $32(33.3)$ & $7(41.2)$ & 0.59 \\
\hline General hospital & $74(65.5)$ & $64(66.7)$ & $10(58.8)$ & \\
\hline $\begin{array}{l}\text { Working hours }(/ \mathrm{w}) \\
\quad(\text { mean } \pm \mathrm{SD})\end{array}$ & $44.3 \pm 8.5$ & $43.0 \pm 8.3$ & $51.2 \pm 6.5$ & $<0.01$ \\
\hline $\begin{array}{l}\text { Days off (days/month) } \\
\quad(\text { mean } \pm \mathrm{SD})\end{array}$ & $9.2 \pm 2.5$ & $9.6 \pm 2.2$ & $7.5 \pm 3.0$ & $<0.01$ \\
\hline Turnover Intention (n, \%) & $41(36.3)$ & $36(37.5)$ & $5(29.4)$ & 0.52 \\
\hline
\end{tabular}


Table 2. Work engagement and burnout of staff midwives and immediate superiors (head midwives/nurses) on maternity and labor wards.

\begin{tabular}{|c|c|c|c|c|}
\hline & Total & Staff midwives & $\begin{array}{l}\text { Immediate } \\
\text { superiors }\end{array}$ & $\mathrm{p}$-value \\
\hline $\mathrm{N}(\%)$ & 113 & $96(85.0 \%)$ & $17(15.0 \%)$ & \\
\hline \multicolumn{5}{|c|}{ Work engagement } \\
\hline Total score $($ mean $\pm \mathrm{SD})$ & $3.12 \pm 0.94$ & $3.00 \pm 0.89$ & $3.82 \pm 0.96$ & $<0.01$ \\
\hline Vigor $($ mean $\pm S D)$ & $2.89 \pm 1.11$ & $2.77 \pm 1.07$ & $3.55 \pm 1.13$ & 0.01 \\
\hline Dedication $($ mean $\pm S D)$ & $3.75 \pm 1.06$ & $3.65 \pm 1.02$ & $4.33 \pm 1.10$ & 0.01 \\
\hline Absorption $($ mean $\pm \mathrm{SD})$ & $2.72 \pm 1.03$ & $2.57 \pm 0.98$ & $3.57 \pm 0.90$ & $<0.01$ \\
\hline \multicolumn{5}{|c|}{ Burnout } \\
\hline Exhaustion (mean $\pm \mathrm{SD})$ & $3.06 \pm 1.24$ & $3.01 \pm 1.21$ & $3.31 \pm 1.43$ & 0.37 \\
\hline Cynicism (mean \pm SD) & $1.73 \pm 1.13$ & $1.69 \pm 1.12$ & $1.92 \pm 1.24$ & 0.46 \\
\hline $\mathrm{PE}($ mean $\pm \mathrm{SD})$ & $2.57 \pm 1.17$ & $2.52 \pm 1.14$ & $2.81 \pm 1.29$ & 0.35 \\
\hline
\end{tabular}

PE: professional efficacy, unpaired t-test.

Table 3. Logistic regression analysis of high work engagement among staff midwives $(\mathrm{n}=$ 96).

\begin{tabular}{ccccc}
\hline & Low WE & High WE & $\begin{array}{c}\text { Crude OR } \\
(95 \% \mathrm{CI})\end{array}$ & $\begin{array}{c}\text { Adjusted OR } \\
(95 \% \mathrm{CI})\end{array}$ \\
\hline $\mathrm{N}$ & 71 & 25 & & \\
Age (years) (mean $\pm \mathrm{SD})$ & $37.2 \pm 8.8$ & $37.9 \pm 7.5$ & $1.01(0.96-1.07)$ & $0.99(0.92-1.07)$ \\
Married (n, \%) & $40(56.3)$ & $18(72.0)$ & $1.99(0.74-5.37)$ & $3.74(0.99-14.12)$ \\
& Immediate superiors' (head midwives/nurses) & \\
WE (mean $\pm \mathrm{SD})$ & $3.80 \pm 0.82$ & $3.46 \pm 1.04$ & $0.65(0.39-1.09)$ & $0.67(0.29-1.54)$ \\
Exhaustion (mean $\pm \mathrm{SD})$ & $3.33 \pm 1.28$ & $4.14 \pm 1.14$ & $1.81(1.15-2.84)^{*}$ & $1.61(0.82-3.15)$ \\
Cynicism (mean $\pm \mathrm{SD})$ & $1.76 \pm 0.76$ & $2.69 \pm 1.58$ & $2.15(1.32-3.49)^{* *}$ & $2.01(1.04-3.90)^{*}$ \\
PE (mean $\pm \mathrm{SD})$ & $2.34 \pm 1.24$ & $2.48 \pm 1.27$ & $1.09(0.75-1.58)$ & $1.93(1.12-3.33)^{*}$ \\
\hline
\end{tabular}

Adjusted for all variables in this table. High WE (very high + high) $=1$, WE: work engagement, OR: odds ratio, PE: professional efficacy, ${ }^{*} \mathrm{p}<0.05,{ }^{* *} \mathrm{p}<0.01$.

wards, and the factors related to work engagement of staff midwives including work engagement and burnout of their immediate superiors.

In previous studies of work engagement assessed by UWES, Irish nurses/ midwives, who worked as a staff on wards in $58 \%$ and as nursing managers in $26 \%$, scored $4.26 \pm 0.49$ [26], and German nursing unit managers who were involved in direct patient care for $30 \%$ scored $4.29 \pm 1.01$ in total score [27]. These mean scores were higher than the mean score $(3.12 \pm 0.94)$ in this study. An international comparison of work engagement among general workers revealed that the level of work engagement of Japanese was also lower than those in other countries [28]. The authors conclude that such differences might be caused partly by the cultural background of the Japanese, where people tend to be reticent about expressing their strong points. In the study, participants tended to understate the work engagement, and one need to be aware of this issue in inter- 
preting the data.

It is well known that midwives have a high level of burnout compared with the general population [3] [4] [5], and are historically likely to be in a state of burnout [29]. Comparing the level of burnout among eight countries, Japanese staff nurses had higher levels of exhaustion and cynicism, and a lower level of professional efficacy than those in other countries [30]. Japanese nurses' burnout scores assessed by MBI-GS showed $4.05 \pm 1.33$ in exhaustion, $2.27 \pm 1.34$ in cynicism, and $2.46 \pm 1.15$ in professional efficacy [31]. Additionally, general Japanese scored $3.86 \pm 1.50$ in exhaustion, $2.32 \pm 1.42$ in cynicism, and $2.41 \pm 1.14$ in professional efficacy [6]. Comparing our data (3.06 \pm 1.24 in exhaustion, $1.73 \pm 1.13$ in cynicism) with these results, midwives in this study may not exposed to higher level of burnout than other groups of Japanese workers.

Interestingly, staff midwives showed a significantly lower level of work engagement than immediate superiors (head midwives/nurses) (Table 2). In contrast, there was no difference in the mean scores of the three subcategories on burnout between staff midwives and immediate superiors. As shown in Table 2, the total score of work engagement was $3.00 \pm 0.89$ among staff midwives, whose scores were considerably low compared with those of nursing professionals in other countries and immediate superiors in Japan. Such a low level of work engagement might be problematic for management of staff midwives working on maternity and labor wards. García-Sierra et al. [21] highlighted the importance of managers' leadership at the ward level for promoting staff midwives' work engagement. In general, work engagement and burnout were reported to have a crossover effect. Team-level work engagement and burnout were related to individual team members' work engagement and burnout among Dutch constabulary officers [19], and there was a crossover effect of burnout between school teachers and their immediate principals [18]. We therefore examined the factors related to high work engagement of staff midwives, including work engagement and burnout of their immediate superiors. In the logistic analysis, work engagement of staff midwives was significantly correlated with the professional efficacy of the immediate superiors (AOR 1.93, 95\% CI 1.12 - 3.33), while it was not correlated with work engagement of their immediate superiors (Table 3). These results suggested that there might be a crossover effect between work engagement of staff midwives and professional efficacy of their immediate superiors. Professional efficacy encompasses occupational accomplishments [9]. A lack of professional efficacy refers to a tendency to negatively evaluate one's work with recipients such as students, pupils, clients, patients, consumers or delinquents, and is accompanied by feelings of inadequacy toward one's work [32]. Work engagement of staff nurses was reported to comprise four influencing factors (impact of nurse managers, organizational antecedents, individual antecedents, and outcomes of engagement), among which individual antecedents included personal traits and family issues other than professional characteristics [21]. Although work engagement and professional efficacy express a positive attitude toward working, there was some difference in their significance. As a result, we 
considered that co-working with immediate superiors who have high professional efficacy possibly increased the work engagement of staff midwives.

Moreover, cynicism of immediate superiors was correlated with high work engagement of staff midwives (AOR 2.01, 95\% CI 1.04 - 3.90). Cynicism reflects indifference or a distant attitude towards working in general [8]. Autonomy is an antecedent of work engagement in nursing [33], and a lack of autonomy reduces work engagement [34]. Therefore, a distant attitude toward work of immediate superiors might induce autonomy toward work among staff midwives, resulting in elevated work engagement of staff midwives.

\section{Limitations}

There are some limitations to this study. Firstly, this study was a complete survey of Hyogo prefecture, which has an average number of midwives for Japan, and was the first examination of work engagement of midwives in Japan; therefore the sample size was not determined. In future studies, we should use larger numbers of hospitals selected by probability sampling and it will be necessary to determine the sample size based on the results of this study.

Secondly, we found a positive correlation between the work engagement of staff midwives and the professional efficacy and cynicism of their superiors, but a cause-and-effect relationship has not been determined yet. To increase the work engagement of staff, we need to reveal how to increase the professional efficacy of immediate superiors and also the staff midwives' autonomy.

Thirdly, this study demonstrated a correlation of mental conditions for work between staff midwives and immediate superiors, while a similar correlation might also be found among co-workers. In a future study, mental conditions for work should be comprehensively examined at the clinical unit level.

\section{Conclusion}

We found that staff midwives in Japan showed very low levels of work engagement compared with their immediate superiors and with nursing professionals in other countries, although there were no differences in burnout between them. High work engagement of staff midwives was correlated to high professional efficacy and cynicism of their immediate superiors, suggesting that there might be crossover effects on mental conditions for work between staff midwives and their immediate superiors working on maternity and labor wards in Japan.

\section{Acknowledgements}

The authors would like to thank all of the study's participants. This study was partially supported by the Society for Women's Health Science Research, Osaka prefecture, Japan (RHOTO 13-B1-004).

\section{References}

[1] Hunter, B. (2001) Emotion Work in Midwifery: A Review of Current Knowledge. Journal of Advanced Nursing, 34, 436-444. 
https://doi.org/10.1046/j.1365-2648.2001.01772.x

[2] Wallbank, S. and Robertson, N. (2008) Midwife and Nurse Responses to Miscarriage, Stillbirth and Neonatal Death: A Critical Review of Qualitative Research. Evidence Based Midwifery, 6, 100-106.

[3] Hildingsson, I., Westlund, K. and Wiklund, I. (2013) Burnout in Swedish Midwives. Sexual \& Reproductive Healthcare: Official Journal of the Swedish Association of Midwives, 4, 87-91.

[4] Jordan, K., Fenwick, J., Slavin, V., Sidebotham, M. and Gamble, J. (2013) Level of Burnout in a Small Population of Australian Midwives. Women and Birth: Journal of the Australian College of Midwives, 26, 125-132.

https://doi.org/10.1016/j.wombi.2013.01.002

[5] Mollart, L., Skinner, V.M., Newing, C. and Foureur, M. (2013) Factors That May Influence Midwives Work-Related Stress and Burnout. Women and Birth: Journal of the Australian College of Midwives, 26, 26-32.

https://doi.org/10.1016/j.wombi.2011.08.002

[6] Schaufeli, W., Shimazu, A. and Taris, T. (2009) Being Driven to Work Excessively Hard the Evaluation of a Two-Factor Measure of Workaholism in the Netherlands and Japan. Cross-Cultural Research, 43, 320-348.

https://doi.org/10.1177/1069397109337239

[7] Schaufeli, W., Leiter, M., Maslach, C. and Jackson, S. (1996) Maslach Burnout Inventory-General Survey. In: Maslach, C., Jackson, S.E. and Leiter, M.P., Eds., The Maslach Burnout Inventory: Test Manual, Consulting Psychologists Press, Palo Alto, CA.

[8] Schaufeli, W., Salanova, M., Gonzalez-Roma, V. and Bakker, A. (2002) The Measurement of Engagement and Burnout: A Two Sample Confirmatory Factor Analytic Approach. Journal of Happiness Stadies, 3, 71-92. https://doi.org/10.1023/A:1015630930326

[9] Schaufeli, W. and Bakker, A. (2004) Job Demands, Job Resources, and Their Relationship with Burnout and Engagement: A Multi-Sample Study. Journal of Organizational Behavior, 25, 293-315. https://doi.org/10.1002/job.248

[10] Simpson, M. (2009) Engagement at Work: A Review of the Literature. International Journal of Nursing Studies, 46, 1012-1024. https://doi.org/10.1016/j.ijnurstu.2008.05.003

[11] Walker, A. and Campbell, K. (2013) Work Readiness of Graduate Nurses and the Impact on Job Satisfaction, Work Engagement and Intention to Temain. Nurse Education Today, 33, 1490-1495. https://doi.org/10.1016/j.nedt.2013.05.008

[12] Nahrgang, J., Morgeson, F. and Hofmann, D. (2011) Safety at Work: A Meta-Analytic Investigation of the Link between Job Demands, Job Resources, Burnout, Engagement, and Safety Outcomes. Journal of Applied Psychology, 96, 71-94. https://doi.org/10.1037/a0021484

[13] Mark, B., Hughes, L., Belyea, M., Chang, Y., Hofmann, D., Jones, C. and Bacon, C. (2007) Does Safety Climate Moderate the Influence of Staffing Adequacy and Work Conditions on Nurse Injuries? Journal of Safety Research, 38, 431-446. https://doi.org/10.1016/j.jsr.2007.04.004

[14] Bacon, C. and Mark, B. (2009) Organizational Effects on Patient Satisfaction in Hospital Medical-Surgical Units. The Journal of Nursing Administration, 39, 220227. https://doi.org/10.1097/NNA.0b013e3181a23d3f

[15] Wang, S. and Liu, Y. (2015) Impact of Professional Nursing Practice Environment and Psychological Empowerment on Nurses' Work Engagement: Test of Structural Equation Modelling. Journal of Nursing Management, 23, 287-296. 
https://doi.org/10.1111/jonm.12124

[16] Van Bogaert, P., Clarke, S., Willems, R. and Mondelaers, M. (2013) Staff Engagement as a Target for Managing Work Environments in Psychiatric Hospitals: Implications for Workforce Stability and Quality of Care. Journal of Clinical Nursing, 22, 1717-1728. https://doi.org/10.1111/j.1365-2702.2012.04341.x

[17] Van Bogaert, P., Wouters, K., Willems, R., Mondelaers, M. and Clarke, S. (2013) Work Engagement Supports Nurse Workforce Stability and Quality of Care: Nursing Team-Level Analysis in Psychiatric Hospitals. Journal of Psychiatric and Mental Health Nursing, 20, 679-686. https://doi.org/10.1111/jpm.12004

[18] Westman, M. and Etzion, D. (1999) The Crossover of Strain from School Principals to Teachers and Vice Versa. Journal of Occupational Health Psychology, 4, 269-278. https://doi.org/10.1037/1076-8998.4.3.269

[19] Bakker, A., Emmerik, H.V. and Euwema, M. (2006) Crossover of Burnout and Engagement in Work Teams. Work and Occupations, 33, 464-489. https://doi.org/10.1177/0730888406291310

[20] Henshaw, A., Clarke, D. and Long, A. (2013) Midwives and Supervisors of Midwives' Perceptions of the Statutory Supervision of Midwifery within the United Kingdom: A Systematic Review. Midwifery, 29, 75-85. https://doi.org/10.1016/j.midw.2011.11.004

[21] García-Sierra, R., Fernández-Castro, J. and Martínez-Zaragoza, F. (2016) Work Engagement in Nursing: An Integrative Review of the Literature. Journal of Nursing Management, 24, E101-E111. https://doi.org/10.1111/jonm.12312

[22] Schaufeli, W., Bakker, A. and Salanova, M. (2006) The Measurement of Work Engagement with a Short Questionnaire: A Cross-National Study. Educational and Psychological Measurement, 66, 701-716. https://doi.org/10.1177/0013164405282471

[23] Shimazu, A., Schaufeli, W., Kosugi, S., Suzuki, A., Nashiwa, H., Kato, A., Sakamoto, M., Irimajiri, H., Amano, S., Hirohata, K. and Goto, R. (2008) Work Engagement in Japan: Validation of the Japanese Version of the Utrecht Work Engagement Scale. Applied Psychology-An International Review-Psychologie Appliquee-Revue Internationale, 57, 510-523. https://doi.org/10.1111/j.1464-0597.2008.00333.x

[24] Kitaoka-Higashiguchi, K., Nakagawa, H., Morikawa, Y., Ishizaki, M., Miura, K., Naruse, Y., Kido, T. and Higashiyama, M. (2004) Construct Validity of the Maslach Burnout Inventory-General Survey. Stress and Health, 20, 255-260. https://doi.org/10.1002/smi.1030

[25] Schaufeli, W. and Bakker, A. (2004) UWES Utrecht Work Engagement Scale Preliminary Manual. Occupational Health Psychology Unit Utrecht University, Utrecht.

[26] Freeney, Y. and Fellenz, M. (2013) Work Engagement as a Key Driver of Quality of Care: A Study with Midwives. Journal of Health Organization and Management, 27, 330-349. https://doi.org/10.1108/JHOM-10-2012-0192

[27] Van Bogaert, P., Adriaenssens, J., Dilles, T., Martens, D., van Rompaey, B. and Timmermans, O. (2014) Impact of Role-, Job- and Organizational Characteristics on Nursing Unit Managers' Work Related Stress and Well-Being. Journal of Advanced Nursing, 70, 2622-2633. https://doi.org/10.1111/jan.12449

[28] Shimazu, A., Schaufeli, W., Miyanaka, D. and Iwata, N. (2010) Why Japanese Workers Show Low Work Engagement: An Item Response Theory Analysis of the Utrecht Work Engagement Scale. BioPsychoSocial Medicine, 4, 17. https://doi.org/10.1186/1751-0759-4-17

[29] Yoshida, Y. and Sandall, J. (2013) Occupational Burnout and Work Factors in Community and Hospital Midwives: A Survey Analysis. Midwifery, 29, 921-926. 
https://doi.org/10.1016/j.midw.2012.11.002

[30] Poghosyan, L., Aiken, L. and Sloane. D. (2009) Factor Structure of the Maslach Burnout Inventory: An Analysis of Data from Large Scale Cross-Sectional Surveys of Nurses from Eight Countries. International Journal of Nursing Studies, 46, 894902. https://doi.org/10.1016/j.ijnurstu.2009.03.004

[31] Kitaoka-Higashiguchi, K. (2005) Burnout as a Developmental Process among Japanese Nurses: Investigation of Leiter's Model. Japan Journal of Nursing Science, 2, 9-16. https://doi.org/10.1111/j.1742-7924.2005.00025.x

[32] Schaufeli, W. and Buunk, B. (1996) Professional Burnout. John Wiley, Chichester.

[33] Bargagliotti, L. (2012) Work Engagement in Nursing: A Concept Analysis. Journal of Advanced Nursing, 68, 1414-1428. https://doi.org/10.1111/j.1365-2648.2011.05859.x

[34] Othman, N. and Nasurdin, A., (2013) Social Support and Work Engagement: A Study of Malaysian Nurses. Journal of Nursing Management, 21, 1083-1090. https://doi.org/10.1111/j.1365-2834.2012.01448.x

Submit or recommend next manuscript to SCIRP and we will provide best service for you:

Accepting pre-submission inquiries through Email, Facebook, LinkedIn, Twitter, etc. A wide selection of journals (inclusive of 9 subjects, more than 200 journals)

Providing 24-hour high-quality service

User-friendly online submission system

Fair and swift peer-review system

Efficient typesetting and proofreading procedure

Display of the result of downloads and visits, as well as the number of cited articles Maximum dissemination of your research work

Submit your manuscript at: http://papersubmission.scirp.org/

Or contact ojn@scirp.org 